\title{
Behavior Effect of Fluoxetine in Presence of Selenium Using Albino Mice
}

\author{
Suhera M. Aburawi ${ }^{1, a^{*}}$, Sumaya A. Baayo ${ }^{2, b}$ \\ 1,2Department of Pharmacology and Clinical Pharmacy \\ Faculty of Pharmacy, University of Tripoli, Tripoli, Libya \\ asmaburawi@yahoo.com, bsabaayo@yahoo.com
}

Keywords: Fluoxetine, Selenium, plus maze, Photoelectric cells, Forced swimming maze.

\begin{abstract}
Depression is a major cause of morbidity worldwide. Fluoxetine is a selective serotonin reuptake inhibitor, and is effective antidepressant medication. Selenium is essential for good health but required only in small amounts.

Aim of the study is to investigate the effects of fluxetine alone and in presence of selenium on anxiety, spontaneous motor activity and antidepressant behavior. Also, the study aims to investigate the effects of selenium on spontaneous motor activity, anxiety measure, and antidepressant behavior, using photoelectric cells, elevated plus maze and forced swimming maze.

Mice were divided into 5 group $(n=6)$. Group 1 (control), administered $1 \%$ tween 80 ( $5 \mathrm{ml} / \mathrm{kg}$ ); group 2 administered selenium $(200 \mu \mathrm{g} / \mathrm{kg})$; group 3 received diazepam as a positive control $(1 \mathrm{mg} / \mathrm{kg})$; group 4 received fluoxetine $(20 \mathrm{mg} / \mathrm{kg})$; while group 5 received combined treatment of fluoxetine and selenium. All drugs injected sub acutely (three doses), mice were intraperitoneally administered at 24, 5, and $1.0 \mathrm{hrs}$ before scoring. All drugs administered as suspension in 1\% Tween 80 (T80). It was injected in volume $5 \mathrm{ml} / \mathrm{kg}$. Plus maze, photoelectric cells and forced swimming maze models were used.

Fluoxetine has no effect on anxiety or locomotor activity; while selenium produced anxiolytic effect without changes on locomotor activity. Fluoxetine has antidepressant activity without any effect on duration of climbing. Selenium induced antidepressant effect with climbing action. Fluoxetine abolish the anxiolytic effect of selenium when administered together, but the combined treatment decreases the locomotor activity. Fluoxetine administration with selenium counteract the antidepressant effect of each other and climbing effect of selenium. Finally, selenium improves anxiety and depression behavior in albino mice, and might be used as an alternative therapy instead of fluoxetine (which treat antidepression only); but it must not be taken in combination with it.
\end{abstract}

\section{Introduction}

Depression is a major disorder that affect approximately $4.3 \%$ of the global population [1]. Men suffer from depression and are more likely to commit suicide than women [2]. Risk of depression may be linked to physical illness in the elderly. Physical disability and chronic pain or medical side effect problems leads to individual breakdown [3].

There are five main types of antidepressant drugs; these are tricyclics, tetracyclics, monoamine oxidase inhibitors, serotonin and noradrenaline reuptake inhibitors, and selective serotonin reuptake inhibitors [4]. Selective serotonin reuptake inhibitors (SSRIs) are effective in treating depression without side effects; an example from this group is Fluoxetine [5]. The mechanism of action of SSRIs is through increasing the extracellular level of serotonin by inhibiting its reuptake into the presynaptic cell; this leads to increasing serotonin bind to the postsynaptic receptor. Selective serotonin reuptake inhibitors have weak affinity for the noradrenalin and dopamine transporter [6].

Selenium is an essential mineral needed for good health, it is required in small amounts. Selenium as selenoproteins is an important antioxidant enzymes. The antioxidant selenoproteins prevent free radicals cellular damage. Free radicals are naturally produced from oxygen metabolism, and may leads to chronic diseases such as cancer [7,8]. Selenoproteins have other roles such as regulating thyroid function and have a role in the immune system [9]. 
Deficiency of selenium may lead to depression; Selenium at a daily dose of $200 \mu \mathrm{g}$ can cure a patient from acute stage of depression and apathy. Selenium is important for blood and bone health, nervous system and brain activity, and preventing mood swings and aging [10].

Aim of the Study: To investigate the effects of fluxetine alone and in the presence of selenium on anxiety, spontaneous motor activity, and antidepressant behavior. Also to investigate the effects of selenium on spontaneous motor activity, anxiety measure, and antidepressant behavior, using photoelectric cells, elevated plus maze and forced swimming maze.

\section{Materials and Methods}

Animals: The experiments were carried out using male albino mice (25-40gm) bred in the animal house of Faculty of Pharmacy- Tripoli University. Standard mice food pellet diet and water were free available. The animals were kept at room temperature $\left(20-25^{\circ} \mathrm{C}\right)$, and on $12 \mathrm{~h}$ dark/light cycle. Animals were kept in laboratory for at least 1 day before testing to acclimate with a new environment.

Drugs: Fluoxetine was obtained from Actavis, Barnstaple, UK; it was administered at a dose of $20 \mathrm{mg} / \mathrm{kg}$ [11]. Diazepam was obtained from Roche, Switzerland; it was administered at a dose of $1 \mathrm{mg} / \mathrm{kg}$ [12]. Selenium was obtained from Jamieson, Toronto, Montreal, Vancouver, Canada; it was administered at a dose of $200 \mu \mathrm{g} / \mathrm{kg}$ [13]. All drugs administered intraperitoneally as suspension in $1 \%$ Tween 80 (T80) [14]. It was injected in volume $5 \mathrm{ml} / \mathrm{kg}$ [15], and were prepared freshly prior to use.

Elevated Plus-Maze: composed of two open arms $(30 * 5 \mathrm{~cm})$ and two close arms $(30 * 5 * 15 \mathrm{~cm})$ that extended from a common central platform $(5 * 5 \mathrm{~cm})$. The apparatus was elevated to height of $45 \mathrm{~cm}$ above floor level [16]. Mice were gently handled by the right hand and placed on the center squire of the maze facing into the close arm.

The different parameters were scored to evaluate anxiolytic effect and spontaneous motor activity in the elevated plus-maze which include: time spent by the mouse in each of the arms, lines crossed in close or open arms, and the number of entries into close or open arms. An arm entry was defined as the entry of all four paws into the arm [17]. The total line crossed, total number of entries were calculated. The total line crossed and the total arm entries $[18,19]$ express the spontaneous motor activity. Anxiety measures was calculated by the time spent in close arm by the total time of the test [19]. The duration of the test was 4 minutes.

Photoelectric Cells: was constructed from plywood (painted white) and measured $72 \times 72 \mathrm{~cm}$, with $36 \mathrm{~cm}$ high walls. Blue lines were drawn on the floor. The lines divided the floor into $16(18 \times 18) \mathrm{cm}$ squares; these lines were used to measure motor activity [20].

Each mouse was placed in the center of the squares, the Horizontal, Ambulatory, Nonambulatory, and Number of movement recorded by monitor which indicate the motor activity. The duration of the test was 4 minutes.

Forced Swimming Maze: Mice were placed individually in glass cylinders (height $27 \mathrm{~cm}$, diameter $15 \mathrm{~cm}$ ) filled with water to a height of $16 \mathrm{~cm}$ (maintained at $23-25^{\circ} \mathrm{C}$ ). the duration of the test was 6 minutes. The time of the two behavior parameters (duration of immobility and duration of climbing) was recorded during last $4 \mathrm{~min}$ of the $6 \mathrm{~min}$ testing period [21]. Immobility behavior is defined as the animal floated on the surface with front paws together and made only those movements with hind limb which were necessary to keep float. Climbing behavior is defined as upward-directed movements of fore paws along the side of the swim chamber [22].

Design of the Work: Pilot studies for sub-acute effect were performed to choose selenium dose, the dose used was $200 \mu \mathrm{g} / \mathrm{kg}$ [13]. Fluoxetine administered at a dose of $20 \mathrm{mg} / \mathrm{kg}$ [11]. Diazepam was administered at a dose of $1 \mathrm{mg} / \mathrm{kg}$ [12] which was used as positive control for anxiolytic behavior. All drugs injected sub acutely (three doses), mice were intraperitoneally administered at 24, 5, and $1.0 \mathrm{hrs}$ before scoring. All drugs administered as suspension in 1\% Tween 80 (T80) [14]. It was injected in volume $5 \mathrm{ml} / \mathrm{kg}$ [15], and were prepared freshly prior to use. 
Mice were divided into 5 groups $(\mathrm{n}=6)$; group 1 (control), mice administered $5 \mathrm{ml} / \mathrm{kg} 1 \% \mathrm{~T} 80$; group 2, mice administered selenium $(200 \mu \mathrm{g} / \mathrm{kg})$; group 3, mice administered diazepam $(1 \mathrm{mg} / \mathrm{kg})$; group 4, mice administered fluoxetine; group 5, administered combined treatment of selenium and fluoxetine. Diazepam treated group was used as positive control for anxiolytic behavior.

Statistical Analysis: Descriptive statistical analysis was performed using computer program SPSS (version 13), also to verify whether the data were normally distributed by using KolmogroveSimirnove test maximum deviation test for goodness of fit. If the parameters were normally distributed, treatments were compared by one-way ANOVA, Post-Hoc test (LSD and Duncan test) was applied. If the parameters were not normally distributed, treatments were compared by the Mann-Whitney $U$ test for unmatched sample. The differences were considered significant at the $P$ value $\leq 0.05$. The values are expressed as the mean \pm standard error.

\section{Results}

\section{Sub-Acute Effect of Fluoxetine in Presence of Selenium}

Elevated Plus Maze: Administration of selenium and diazepam alone showed significant decrease in anxiety measures $(p \leq 0.05)$, compared to control group. Diazepam produced a more significant decrease in anxiety measures compared to selenium treated group $(p \leq 0.05)$. Fluoxetine $20 \mathrm{mg} / \mathrm{kg}$ administration and the combined treatment of selenium with fluoxetine did not induce significant change in the anxiety measures $(p>0.05)$ compared to control group; but both groups showed significant increase in anxiety measures compared to selenium or diazepam treated groups (Fig. 1). Total lines and total entries did not significant change after administration of any of the treatments $(p>0.05)$.

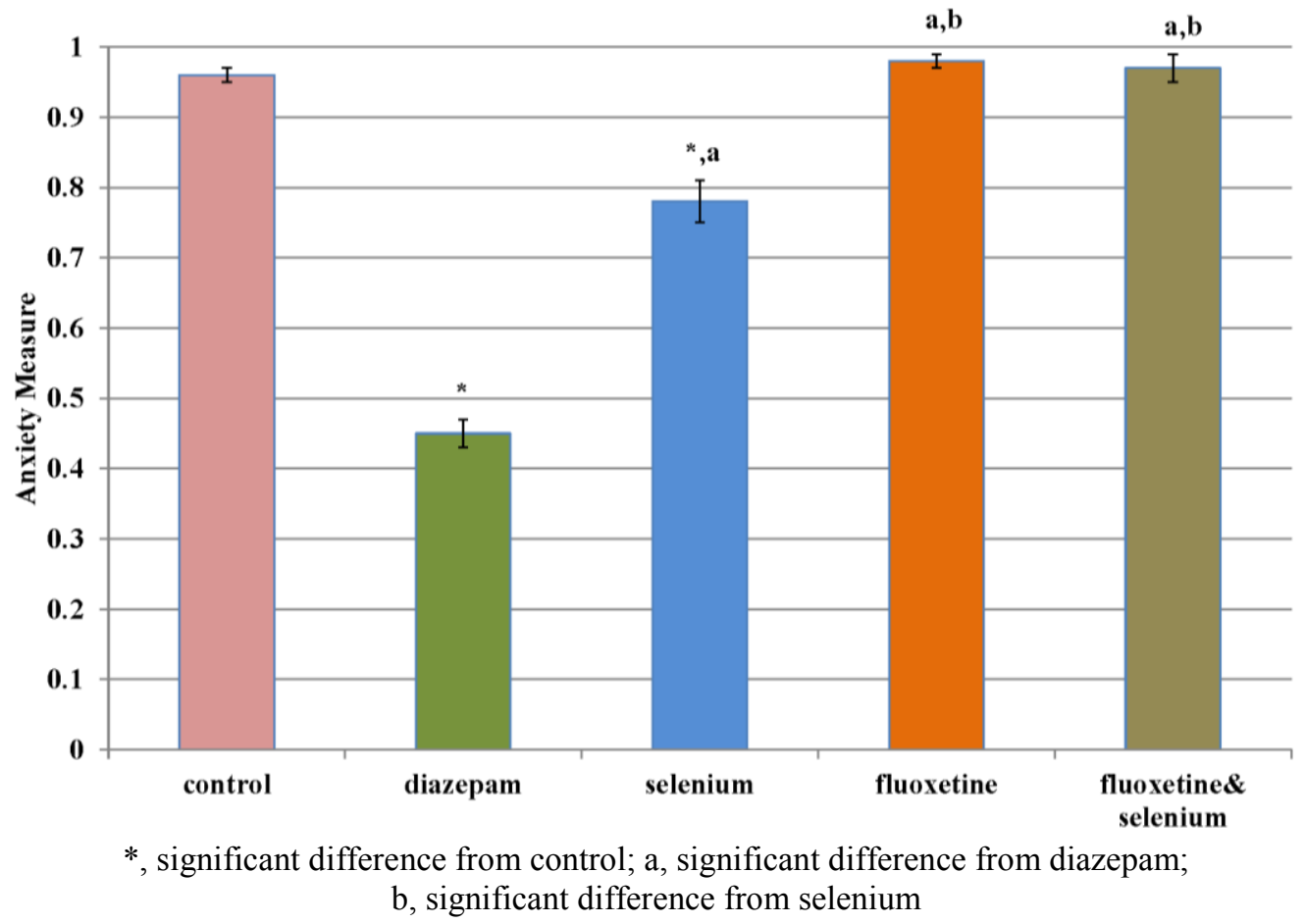

Figure 1. Anxiolytic effect of selenium, fluoxetine or the combination using elevated plus maze.

Photoelectric Cells: Ambulatory, non-Ambulatory, and number of movements significantly decreased after administration of diazepam, and combined treatment of selenium with fluoxetine $(p \leq 0.05)$, compared to control, selenium or fluoxetine treated groups; while the administration of selenium and fluoxetine each alone did not show significant change in the ambulatory, nonambulatory, and number of movements ( $p>0.05$ ), compared to control group (Fig. 2). 


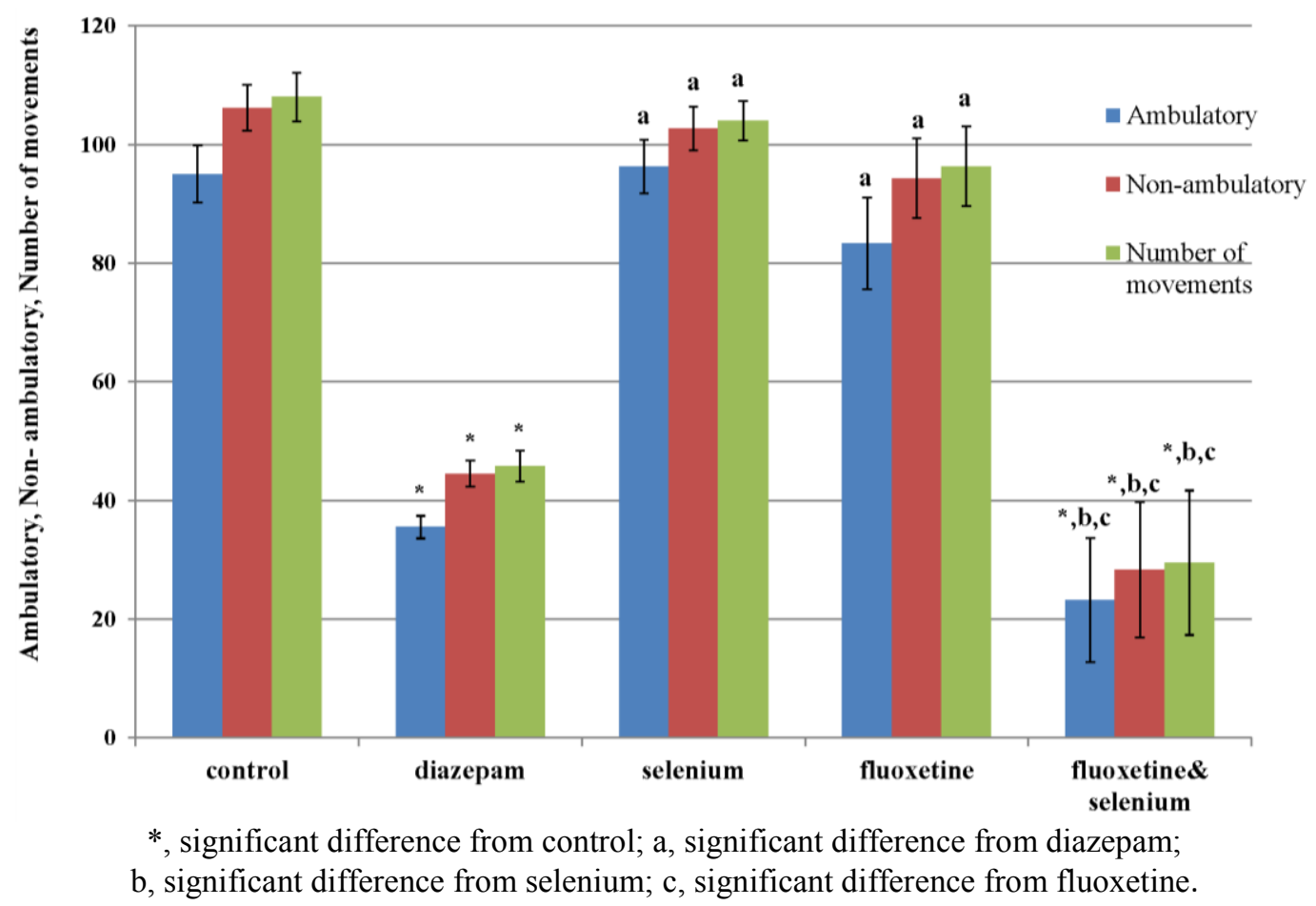

Figure 2. Locomotor activity of selenium, fluoxetine or combined treatment using photoelectric cells.

\section{Forced Swimming Maze}

Administration of selenium, and fluoxetine showed significant decrease in the duration of immobility $(p \leq 0.05)$, compared to control group; while the combined treatment of selenium with fluoxetine did not show significant change in the duration of immobility $(p>0.05)$, compared to control group; but showed significant increase the duration of immobility compared to selenium, or fluoxetine treated groups (Fig. 3).

The duration of climbing significantly increased after administration of selenium $(p \leq 0.05)$, compared to control group; while fluoxetine, and combined treatment of selenium with fluoxetine did not show change in the duration of climbing ( $p>0.05)$, compared to control group; but significant decrease the duration of climbing, compared to selenium treated group (Fig. 3).

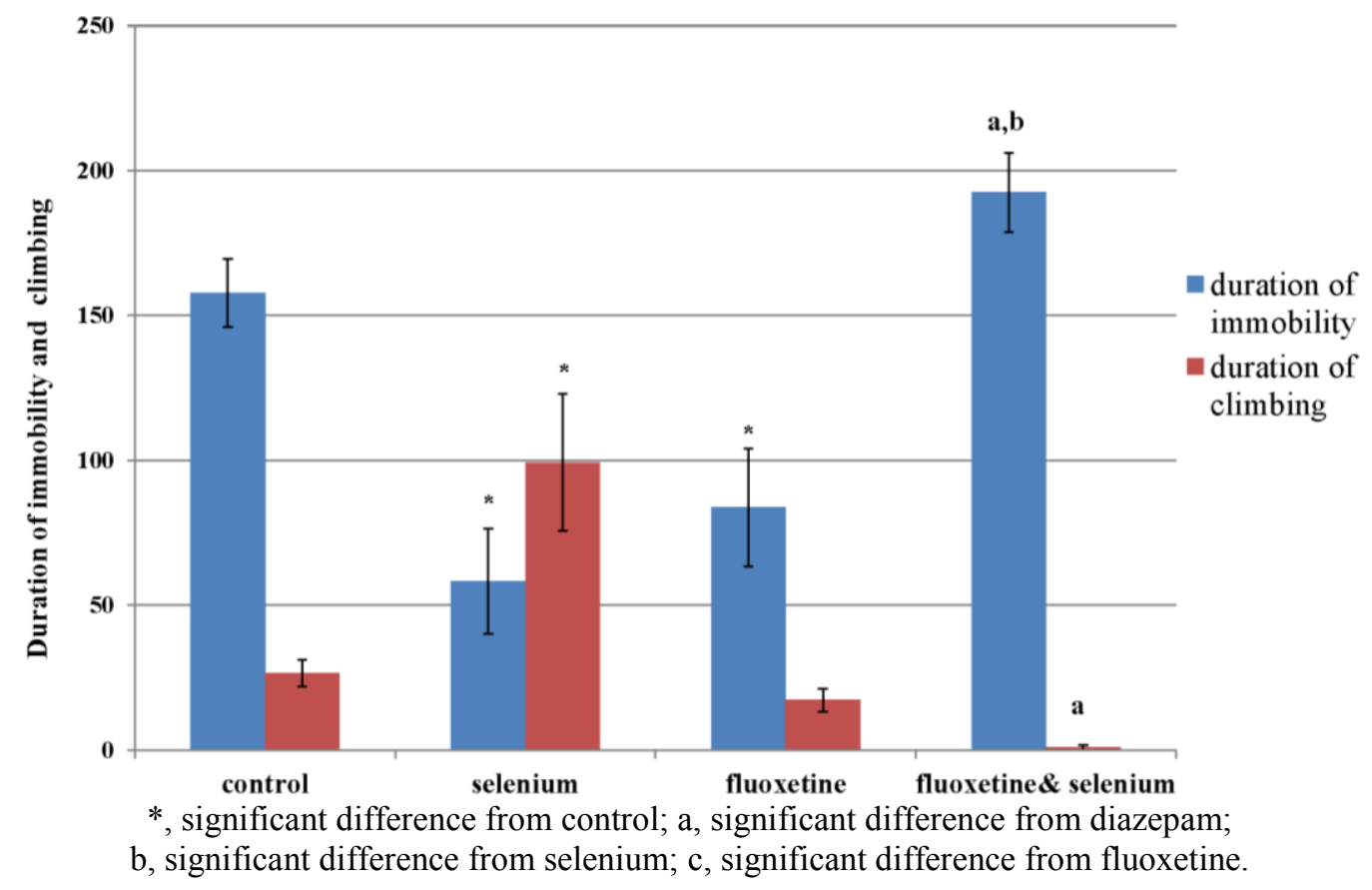

Figure 3. Antidepressant effect of fluoxetine in presence of selenium using forced swimming maze. 


\section{Discussion and Conclusion}

Antidepressants are drugs that relieve the symptoms of depression; they were first developed in the 1950s and have been used regularly since then [4]. Selenium is an antioxidant, and is essential to brain function; increases in dietary selenium, especially in deficient people, improve mood and depressive symptoms [23]. In this work, we studied the effect of fluoxetine as selective serotonin reuptake inhibitors. The action of fluoxetine in presence of selenium was investigated.

The present study used three different models for the measurement of anxiety, locomotor activity and antidepressant effect. These models were elevated plus maze, photoelectric cells, and forced swimming maze. The elevated plus-maze test has become the most widely used animal model for the study of drug effects on anxiety and locomotor activity [24]. This model is rapid test, economy, simple and it does not require lengthy training procedures involving the use of food water deprivation or electric shock [18]. A drug produce anxiolytic effect is measured by decreasing anxiety measure [19]. The increase or decrease in the total lines and total number of entries into open and close arms indicate that there is an increase or decrease in spontaneous motor activity which reflect the effect on the CNS (stimulant or sedative, respectively).

Photoelectric cells test provides simultaneous measures of locomotion [25]. The increase or decrease in ambulatory, non-ambulatory, or the number of movements indicate the increase or decrease in locomotor activity.

Among all animal models, the forced swimming test remains one of the most used tools for screening antidepressants. Forced swimming test is a good screening tool with good reliability and predictive validity [26]. A decrease in the duration of immobility is indicative of an antidepressantlike effect [27]; the increase in both swimming and climbing behaviors in forced swimming test occurs when the animal is treated by a drug which increases serotonergic and/or noradrenergic levels in the nerve terminals [28].

Diazepam, produced anxiolytic and sedative effect and it has been used in this work as positive control. Diazepam is benzodiazepines agonist which activate benzodiazepines receptors leads to enhance the effect of the gamma-aminobutyric acid (GABA) at $\mathrm{GABA}_{\mathrm{A}}$ receptor, resulting in sedative, hypnotic, anxiolytic, anticonvulsant and muscle relaxant properties [29]. Diazepam at the dose used, produced anxiolytic effect (decrease anxiety measures) without affecting motor activity (no effect on the total lines or total entries by using plus maze model; while decreasing the motor activity using photoelectric cells model). Benzodiazepines might be used in the treatment of acute anxiety, they bring about rapid relief of symptoms but not recommended for long term due to lack of long-term effectiveness [30] and might lead to sedative effect [31].

Selenium induced anxiolytic effect. This effect has been previously investigated by Ghisleni and Kazlauckas [32]; it was found that Diphenyl diselenide produced signs of an anxiolytic action. Selenium anxiolytic effect might due that it helps the synthesis of GABA [33]. Selenium did not produce any significant change on spontaneous motor activity and that agree with previous study concluded that selenium has antidepressant action on mice without accompanying changes in spontaneous motor activity [34]. Selenium produced antidepressant effect that might be due to noradrenergic mechanism, where the duration of climbing was increased compared to the control treated group. It was concluded that simple selenium containing molecule significantly reduced the immobility time and has antidepressant-like action using mouse forced swimming test [34]; other study showed that organoselenium compound produces an antidepressant-like effect in forced swimming test that seems to be dependent on its interaction with noradrenergic and dopaminergic systems, but not with serotonergic system [35].

Fluoxetine did not produce anxiolytic effect; a study has been demonstrated that acute administration of fluoxetine at a dose of $20 \mathrm{mg} / \mathrm{kg}$ might produce anxiogenic effects in elevated plus-maze test; while chronic administration of fluoxetine produced anxiolytic effect [36]. The anxiolytic effect of fluoxetine is due to SSRIs mechanism which has high affinity for at least four $5 \mathrm{HT}$ receptor subtypes including $5 \mathrm{HT}_{\mathrm{A}}$ [37]. In the present study fluoxetine did not induce anxiolytic effect, this might be due to that fluoxetine dose and sub-acute administration were not enough to produce significant effect as chronic administration. 
Fluoxetine did not affect the spontaneous motor activity which was observed in both models elevated plus maze and photoelectric cells. It was reported that fluoxetine produced some acute anxiolytic-like activity, without affecting locomotor activity by using elevated plus maze [38]. Fluoxetine decreased the spontaneous motor activity when used in combination with selenium by using photoelectric cells test. Selenium [33] or fluoxetine [39] increases GABA levels; this effect was not significant to be observed when each administered alone. The combined treatment of fluoxetine with selenium might produce significant increase in GABA levels since a decrease in spontaneous motor activity was observed [39].

Fluoxetine induced antidepressant effect without climbing action; this agree with [40] who demonstrated that fluoxetine reduces the immobility time in forced swimming test without affecting the climbing. This is due to fluoxetine is selective to increase the extracellular level of serotonin by inhibiting its reuptake into the presynaptic cell [5].

Antidepressant effect of selenium was observed, selenium might have noradrenergic mechanism $[35,41]$, since the duration of climbing was increased.

Administration of fluoxetine with selenium did not produce antidepressant effect, also the noradrenergic effect observed by selenium was abolished when administered with fluoxetine; this is due to that fluoxetine produces induction to all $\mathrm{CYP}_{450}$ isoenzymes which is responsible for the metabolism of selenium [42], leading to accelerates the metabolism of selenium. Whereas selenium interferes with mechanism of action of fluoxetine by activation of Na-k ATPase enzyme leading to activation of serotonin reuptake [43]; where fluoxetine produces its antidepressant effect through the inhibition of Na-k ATPase enzyme leading to inhibit serotonin reuptake [44].

\section{Conclusion}

Fluoxetine has no effect on anxiety or locomotor activity; while selenium produced anxiolytic effect without changes on locomotor activity. Fluoxetine has antidepressant activity without any effect on duration of climbing. Selenium induced antidepressant effect with climbing action. Fluoxetine abolish the anxiolytic effect of selenium when administered together, but the combined treatment decreases the locomotor activity. Fluoxetine administration with selenium counteract the antidepressant effect of each other and climbing effect of selenium. Finally, selenium improves anxiety and depression behavior in albino mice, and might be used as an alternative therapy instead of fluoxetine to treat depression; but it must not be taken in combination with it.

\section{References}

[1] T. Vos, Years lived with disability (YLDs) for 1160 sequelae of 289 diseases and injuries 1990-2010. A Systematic Analysis for the Global Burden of Disease Study, Lancet. 380 (2012) 2163-2196.

[2] L. Robinson, J. Segal, M. Smith, Depression in men, Helpguide Organization, 2013. Available: http://www.helpguide.org.

[3] M. Smith, L. Robinson, J. Segal, Depression in older adults and the elderly, 2013. Available: http://www.helpguide.org.

[4] C. Chilvers et al., Antidepressant drugs and generic counselling for treatment of major depression in primary care: randomised trial with patient preference compares antidepressants and counseling, Brit. Med. J. 322(7289) (2001) 772-775.

[5] R.A. Harrigan, W.J. Brady, ECG abnormalities in tricyclic antidepressant ingestion, The American Journal of Emergency Medicine. 17(4) (1999) 387-393.

[6] S.H. Preskorn et al., Selective serotonin reuptake inhibitors, in: Antidepressants: past, present and future, Verlag Berlin, Heidelberg, 2004, pp. 241-262. 
[7] S.B. Goldhaber, Trace element risk assessment: essentiality vs. toxicity, Regulatory Toxicology and Pharmacology. 38(2) (2003) 232-242.

[8] C.D. Thomson, Assessment of requirements for selenium and adequacy of selenium status: a review. Eur. J. Clin. Nutr. 58(3) (2004) 391-402.

[9] G.F. Combs, W.P. Gray, Chemo preventive agents: selenium, Pharmacology and Therapeutics. 79(3) (1998) 179-192.

[10] K. Weber, Selenium and depression, 2012. Available: http://www .boost mood.com.

[11] S. Jayesh, A. Ashish, T. Chandrabhanub, Evaluation of anwtidepressant like activity of curcumin and its combination with fluoxetine and imipramine: An acute and chronic study, Acta. Poloniae Pharmaceutica. 68 (2011) 769-775.

[12] B. Naghibi, F. Rayatnia, Co-administration of sub effective anxiolytic doses of diazepam and hydroxyzine in elevated zero-maze in mice, Psychiatry Investig. 8 (2010) 169-173.

[13] C.R. Jesse et al., Evidence for the involvement of the serotonergic 5-HT2A/C and 5-HT3 receptors in the antidepressant-like effect caused by oral administration of bis selenide in mice, Progress in Neuro-Psychopharmacology and Biological Psychiatry. 34(2) (2010) 294302.

[14] Z. Rogoz, G. Skuza, B. Legutko, Repeated treatment with mirtazapine induces brain-derived neurotrophic factor gene expression in rats, J. Physiol. Pharmacol. 56 (2005) 661-671.

[15] A. Swayeh et al., Nitroparacetamol exhibits anti-inflammatory and anti-nociceptive activity, Brit. J. Pharmacol. 130 (2000) 1453-1456.

[16] C. Vinader-Caerols et al., Acute effects of maprotiline on learning, anxiety, activity and analgesia in male and female mice, Acta Neurobiologiae Experiment. 66(1) (2006) 23-31.

[17] S. Kumar, A. Sharma, Anti-anxiety activity studies on homoeopathic formulations of Turnera aphrodisiaca ward, Evidence-based Complementary and Alternative Medicine. 2(1) (2005) 117-119.

[18] R.J. Rodgers, Animal models of anxiety: where next? Behav. Pharmacol. 8 (1997) 477-496.

[19] S.M. Aburawi, Study of neuro chemical mechanisms involved in tolerance and physical dependence to traizolam in experimental animals, Ph.D. Thesis, Cairo University, 1999.

[20] S. Ueki, H. Sugano, A quantitative method for continuous recording of spontaneous activity in small animals, Jap. J. Pharmacol. 17 (1967) 82-89.

[21] L.B. Rojeck, Z. Kalodera, I. Samarzija, The antidepressant activity of Hypericum perforatum L. measured by two experimental methods on mice, Acta Pharma. 54 (2004) 157-162.

[22] J.F. Cryan, M.E. Page, I. Luki, Noradrenergic lesions differentially alter the antidepressant like effects of reboxetine in a modified forced swim test, Eur. J. Pharmacol. 436 (2002) 179205.

[23] W.D. Brandy, Selenium and depression studies, 2013. Available: http://www.livestrong.com.

[24] A. Holmes et al., Behavioral profile of wild mice in the elevated plus-maze test for anxiety, Physiol. Behav. 71 (2000) 509-516.

[25] J. Podhorna, R.E. Brown, Strain differences in activity and emotionality do not account for differences in learning and memory performance between C57BL/6 and DBA/2 mice, Genes. Brain. Behav. 1 (2002) 96-110.

[26] B. Demouliere, F. Chenu, M. Bourin, Forced swimming test in mice: a review of antidepressant activity, Psychopharmacol. 177 (2005) 245-255. 
[27] R.D. Porsolt, A. Bertin, M. Jalfre, Behavioral despair in mice: a primary screening test for antidepressants, Arch. Int. Pharmacodyn. Ther. 229(2) (1977) 327-336.

[28] J.P. Reneric, I. Lucki, Antidepressant behavioral effects by dual inhibition of monoamine reuptake in the rat forced swimming test, Psychopharmacol. 136 (1998) 190-197.

[29] C. Michael et al., Integrated Pharmacology (2nd ed.), C.V. Mosby, 2002.

[30] A. McIntosh, A. Cohen, N. Turnbull, Clinical guidelines and evidence review for panic disorder and generalized anxiety disorder, National Institute for Clinical Excellence, 2004, pp. 165-166.

[31] M.J. Rapoport, K.L. Lanctôt, D.L. Streiner, Benzodiazepine use and driving: a meta-analysis, J. Clin. Psychiatry. 70 (2009) 663-673.

[32] G. Ghisleni, V. Kazlauckas, Diphenyl diselenide exerts anxiolytic-like effect in Wistar rats: Putative roles of GABAA and 5HT receptors, Prog. Neuropsycho Pharmacol. Biol. Psychiatry. 32 (2008) 1508-1509.

[33] T. Wahls, Multiple Sclerosis, 2008. Available: http://www.terrywahls.com.

[34] C.E.S. Oliveira et al., The antidepressant-like action of a simple selenium-containing molecule, methyl phenyl selenide, in mice, Eur. J. Pharmacol. 690(1) (2012) 119-123.

[35] T. Posser et al., Antidepressant like effect of organo selenium compound ebselen in mice; Evidence of the involvement of the monoaminergic system, Eur. J. Pharmacol. 602(1) (2009) $1-5$.

[36] M. Kurt, A.C. Arik, S. Celik, The effects of sertraline and fluoxetine on anxiety in the elevated plus-maze test in mice, J. Basic. Clin. Physiol. Pharmaco. 11 (2000) 173-180.

[37] W.K. Kroeze, L.R. Roth, The molecular biology of 5HT receptors: Therapeutic implications for the interface of mood and psychosis, Biol. Psychiatry. 44 (1998) 1128-1142.

[38] G.B. Varty et al., The Gerbil elevated plus-maze I: Behavioral characterization and pharmacological validation, Neuro Psycho Pharmacol. 27 (2002) 357-370.

[39] R.T. Robinson, B.C. Drafts, J.L. Fisher, Fluoxetine increases GABA(A) receptor activity through a novel modulatory site, J. Pharmacol. Exp. Ther. 304(3) (2003) 978-984.

[40] S. Mora et al., Anxiolytic and antidepressant-like effects of the hydroalcoholic extract from Aloysia polystachya in rats, Pharmacol. Bioch. Behav. 82 (2005) 373-378.

[41] K. Lobato et al., $\alpha$-Tocopherol administration produces an antidepressant-like effect in predictive animal models of depression, Behav. Br. Res. 209(2) (2010) 249-259.

[42] N.B. Sandson, S.C. Armstrong, L. Kelly, An overview of psychotropic drug-drug interactions, Psychosomatics. 46 (2005) 464-494.

[43] B. Nehru, A. Iyer, Effect of selenium on lead-induced neurotoxicity in different brain regions of adult rats, J. Environ. Pathol. Toxicol. Oncol. 13 (1994) 265-268.

[44] L.M. Zanatta et al., In vivo and in vitro effect of imipramine and fluoxetine on $\mathrm{Na}+, \mathrm{K}+-$ ATPase activity in synaptic plasma membranes from the cerebral cortex of rats, Braz. J. Med. Biolog. Res. 34 (2001) 1265-1269. 